\title{
Variation in habitat preference and population structure among three species of the Lake Malawi cichlid genus Protomelas
}

\author{
RICARDO PEREYRA, ${ }^{*}$ MARTIN I. TAYLOR, * GEORGE F. TURNER † and CIRORICO \\ *School of Biological Sciences, University of East Anglia, Norwich NR4 7TJ, UK, †Department of Biological Sciences, University of \\ Hull, HU6 7RX, UK, ¥Estación Biológica de Doñana, CSIC, Avenue Ma Luisa s/n Pabellón del Perú, Apartado de correos 1050,41013 \\ Sevilla, Spain
}

\begin{abstract}
Several studies have demonstrated strong population structuring over small distances in the rocky-shore mbuna cichlid fishes from Lake Malawi, suggesting the potential for allopatric speciation. However, many endemic Lake Malawi cichlids are neither mbuna, nor confined to rocky shores. Using microsatellites, we investigated the population structure in three species of the non-mbuna genus Protomelas. The rocky-shore P. taeniolatus showed high levels of population structure even over distances of less than $1 \mathrm{~km}$, while the sandy-shore species P. similis showed no significant structure over distances up to $21 \mathrm{~km}$. Protomelas fenestratus, which is generally found at the interface between rocks and sand, also showed low levels of population structure. Our results suggest that the model of allopatric speciation based on habitat fragmentation within the current lake basin may be equally applicable to rocky-shore non-mbuna as to mbuna, but that an alternative model is required to explain speciation among sandy-shore species as well as the deep-water and pelagic species.
\end{abstract}

Keywords: cichlid fishes, Lake Malawi, microsatellite DNA, Protomelas, population structure, speciation

\section{Introduction}

Lake Malawi is believed to be inhabited by more species of fish than any other lake, the great majority of them being endemic haplochromine cichlids, which represent one of the largest and fastest known adaptive radiations (Turner 1999). The most taxon-rich Malawi cichlids are the rockyshore 'mbuna' which are presently believed to make up about 240 of the estimated 620 endemic haplochromine species. It has been proposed that speciation in mbuna has taken place allopatrically on isolated patches of rocky habitat within the lake (Fryer 1959; Fryer \& Iles 1972; Ribbink et al. 1983). Later studies have demonstrated finescale population structuring and independent local origins of colour forms, consistent with restricted movement of individuals between populations within the lake, as required

Correspondence: George Turner. Fax: 441482 465458;

E-mail: g.f.turner@hull.ac.uk by parapatric and allopatric models (e.g. Arnegard et al. 1999; Markert et al. 1999; Danley et al. 2000; Rico \& Turner 2002; Rico et al. 2003).

However, some 375 of the recent maximal estimate of 620 species of haplochromine species endemic to Lake Malawi are not mbuna. Some are specialized to live on rocky shores (Fryer 1959; Ribbink et al. 1983; Konings 2001), but most species are found in other habitats, such as sandy shores, deep waters or even surface offshore waters (the 'pelagic zone'). It has been suggested that just as rocky habitats are patchily distributed and the rocky-shore specialists find other habitats a barrier to dispersal, so species specialized to other habitats, such as sandy shores, will also find barriers to dispersal, in the form of rocky shores or deep-water habitats (Fryer \& Iles 1972).

The inshore Copadichromis ‘virginalis kajose' showed far less population structuring than mbuna (Taylor \& Verheyen 2001), while three offshore Diplotaxodon species showed minimal structuring even over hundreds of kilometres 
(Shaw et al. 2000). Thus, a different model of speciation may be needed for these mid-water zooplankton feeders, perhaps involving sympatric speciation (Turner 1994; Shaw et al. 2000), or subdivision of the lake by severe drops in its water level (Sturmbauer et al. 2001).

To gain further insight into the generality of these studies in relation to speciation within Lake Malawi cichlids, we investigated population structure in three congeneric species of non-mbuna cichlids endemic to Lake Malawi, the rocky-shore specialist Protomelas taeniolatus, the sandy/ weedy-shore species Protomelas similis and Protomelas fenestratus, a species generally found near the interface between rocky and sandy habitats. On the basis of the hypothesis put forward by Fryer \& Iles (1972), it was predicted that all three species would show high levels of population structuring over relatively small spatial scales, as previously noted for the rocky-shore mbuna cichlids. Arguably, it would also be consistent with their prediction if the sand and rock specialists (P. similis and P. taeniolatus) both showed fine-grained population structure, while the more generalist P. fenestratus did not. However, should P. taeniolatus show considerably greater population structure than P. similis (and perhaps P. fenestratus as well), we might have to invoke a different model to explain speciation in sandy-shore cichlid species, while if none of the three species showed much population structure, it would suggest that the mbuna cichlids are probably unusual, indeed perhaps unique, among Malawi cichlids in their susceptibility to population fragmentation.

\section{Materials and methods}

Protomelas is a genus containing about 15 described species, all endemic to Lake Malawi, its catchment and the catchment of the outflowing Shire River (Eccles \& Trewavas 1989; Konings 2001). Protomelas taeniolatus is a specialized rockyshore species (Ribbink et al. 1983). Males are seasonally territorial and females guard free-swimming fry (Robinson \& Ribbink 1998). These life history traits, along with its morphological similarity to its congeners, suggest that $\mathrm{P}$. taeniolatus has invaded the rocky habitat independently from the mbuna. Protomelas similis inhabits shallow water (Fryer 1959; Konings 2001), feeding largely on the leaves of higher plants (Fryer \& Iles 1972). Protomelas fenestratus lives over rock and sand, particularly at the rock-sand interface near the shoreline (Eccles \& Trewavas 1989). It often feeds by blowing loose sediment off the substrate to search for edible material concealed beneath (Konings 2001).

Although we attempted to sample all three species from the same locations, sampling was constrained by the scarcity or absence of one or more species at particular sites. Individuals of $\mathrm{P}$. taeniolatus and $\mathrm{P}$. fenestratus were sampled from the rocky shores at seven sites from the Lake Malawi shoreline: two from the central western shore and five near the southern end of the lake (Fig. 1). Although P. similis is reported to have a lake-wide distribution (Eccles \& Trewavas 1989; Konings 2001), and was studied at Nkhata Bay in the 1950s by Fryer (1959), we were unable to find this species at this location. Specimens of P. similis were collected from five different sandy areas separated by rocky patches around the Nankumba Peninsula (Fig. 1). Samples were collected from each site using SCUBA with monofilament nets, and fin clips preserved in 100\% ethanol.

DNA was extracted following the method described by Aljanabi \& Martinez (1997). Samples were screened for variation at five polymorphic microsatellite loci, all of which are perfect dinucleotide repeats: UNH001, UNH002 (Kellogg et al. 1995); UME002, UME003 (Parker \& Kornfield 1996), and Pzeb3 (van Oppen et al. 1997). The 10- $\mu \mathrm{L}$ polymerase chain reactions consisted of $1 \mu \mathrm{L}$ (c. $20 \mathrm{ng}$ ) of template DNA, $1.0 \mu \mathrm{m}$ each primer (one of which was dye-labelled FAM, HEX, or NED), $200 \mu \mathrm{m}$ of each dNTP, 0.50 units of Taq polymerase (Bioline), $1 \mu \mathrm{L}$ of $10 \times$ reaction buffer and $2.5 \mathrm{~mm} \mathrm{MgCl}_{2}$ (Bioline). Reactions were denatured for $3 \mathrm{~min}$ at $94{ }^{\circ} \mathrm{C}$, followed by seven cycles of $92{ }^{\circ} \mathrm{C}$ for $20 \mathrm{~s}, \mathrm{~A}_{1}{ }^{\circ} \mathrm{C}$ for $20 \mathrm{~s}$ and $72{ }^{\circ} \mathrm{C}$ for $30 \mathrm{~s}$, followed by 23 cycles of $89^{\circ} \mathrm{C}$ for $20 \mathrm{~s}, \mathrm{~A}_{2}{ }^{\circ} \mathrm{C}$ for $20 \mathrm{~s}, 72^{\circ} \mathrm{C}$ for $20 \mathrm{~s}$, followed by $20^{\circ} \mathrm{C}$ for $4 \mathrm{~min}$. The annealing temperatures $\left(\mathrm{A}_{1}\right.$ and $\left.\mathrm{A}_{2}\right)$ were 52 and $55^{\circ} \mathrm{C}$ for UNH001, 53 and $55^{\circ} \mathrm{C}$ for UNH002, 53 and $55^{\circ} \mathrm{C}$ for UME003, 59 and $59{ }^{\circ} \mathrm{C}$ for UME002 and 49 and $51{ }^{\circ} \mathrm{C}$ for Pzeb3. The polymerase chain reaction products were then multiplexed and resolved on an ABI 377 automated sequencer (P. taeniolatus) or an $\mathrm{ABI} 3700$ sequencer (P. fenestratus and P. similis) (Applied Biosystems) using a ROX 400 size standard. genescan 3.7 and genotyper 3.7 software (Applied Biosystems) were used for allele sizing.

Exact tests of linkage disequilibrium were carried out using genepop 3.3 (Raymond \& Rousset 1995). Allele frequencies, observed and unbiased expected heterozygosities under Hardy-Weinberg expectations were obtained with pop100gene (http://www.ensam.inra.fr/URLB). Departures from Hardy-Weinberg equilibrium were tested following Weir \& Cockerham (1984), implemented by genepop 3.3 (Raymond \& Rousset 1995). Significance levels were determined using the Markov chain method (5000 dememorizations, 100 batches, 2000 iterations per batch).

fstat 2.9.3 (Goudet 2001) was used to estimate population differentiation using the F-statistic $\theta$, taking into account departures from Hardy-Weinberg equilibrium, and $\mathrm{R}_{\mathrm{ST}}$ calc 2.2 (Goodman 1997) to estimate unbiased $\mathrm{R}_{\mathrm{ST}}$, which corrects for variance among loci and sample sizes among populations. G-statistics were calculated with 2000 permutations and 2000 bootstraps to estimate the significance of these analyses. F-statistics may be underestimated because of the high mutation rates of microsatellites (Balloux et al. 2000). Consequently, Fisher's exact tests using genepop 3.3 (Raymond \& Rousset 1995), were 


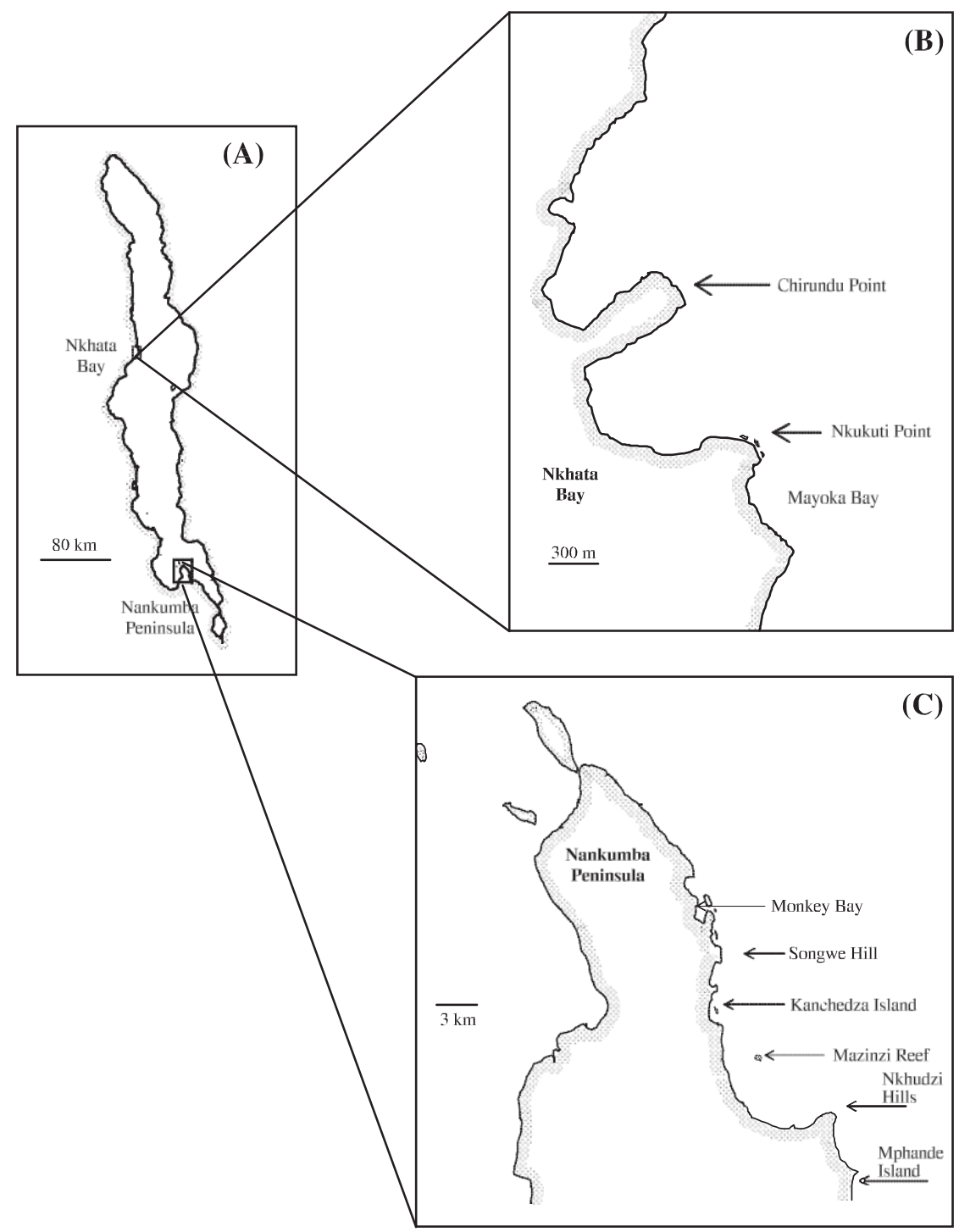

Fig. 1 Sampling sites, showing (A) the overall location in Lake Malawi, (B) the sample sites on the central west coast of the lake and (C) those in the south of the lake. Over the entire sampling area, the distance is approximately $280 \mathrm{~km}$, mostly sandy beaches or muddy bays with occasional rocky headlands and islands.

performed to test for differences in allele frequencies between populations as another indicator of population subdivision, with significance levels determined using the Markov chain method (5000 dememorizations, 100 batches, 2000 iterations per batch). Results (data not shown) were very similar to those for $\mathrm{F}_{\mathrm{ST}}$.

\section{Results}

Significant overall population structuring was detected for Protomelas taeniolatus (overall $\theta=0.026, \mathrm{P}<0.001 ; \mathrm{R}_{\mathrm{ST}}=01082$ $\mathrm{P}<0.001)$. Pairwise $\mathrm{F}_{\mathrm{ST}}(\theta)$ values indicated significant differentiation among all pairs of populations, although the comparison between the neighbouring Kanchedza Island and Mazinzi Reef was non-significant after Bonferroni correction ( $\mathrm{P}=0.016$ : Table 1$)$. Two further pairwise comparisons were not significantly different for the $\mathrm{R}_{\mathrm{ST}}$-based fixation index, namely Songwe Hill vs. Kanchedza Island ( $\mathrm{P}=0.454)$ and Nkukuti Point vs. Chirundu Point $(\mathrm{P}=0.066)$, but deviated significantly from zero with $\theta$ estimates $(\mathrm{P}<$ 0.001 for both). Finally, fixation indexes between Chirundu Point and Nkhudzi Hills, the northernmost sampled population in Nkhata Bay and the southernmost in the Nankumba Peninsula respectively, also indicated significant differences between regions (both $\mathrm{P}<0.001$ ).

Estimates of population structure $(\theta)$ also revealed significant differentiation $(\theta=0.012, \mathrm{P}<0.001)$ over all Protomelas fenestratus populations (Table 2). Although there was a clear difference between northern and southern regions in both $\theta$ and $\mathrm{R}_{\mathrm{ST}}$, Mphande Island was differentiated from other southern populations only by $\theta$ (Table 1 ).

Estimates of population subdivision revealed no significant differences either over all P. similis populations (Table 2), or between individual populations (Table 1). 
Table 1 Estimates of population differentiation between adjacent samples taken from Protomelas populations in Nankumba Peninsula (first six comparisons) and Nkhata Bay (Nkukuti-Chirundu) and for populations representing the whole sampled range (Nkhudzi-Chirundu)

\begin{tabular}{|c|c|c|c|c|c|c|c|c|}
\hline \multirow[b]{2}{*}{ Comparison } & \multirow{2}{*}{$\begin{array}{l}\text { Distance } \\
(\mathrm{km})\end{array}$} & \multirow[b]{2}{*}{ Intervening substrate } & \multicolumn{2}{|c|}{ P. taeniolatus } & \multicolumn{2}{|c|}{ P. fenestratus } & \multicolumn{2}{|c|}{ P. similis } \\
\hline & & & $\theta_{\mathrm{ST}}$ & $\mathrm{R}_{\mathrm{ST}}$ & $\theta_{\mathrm{ST}}$ & $\mathrm{R}_{\mathrm{ST}}$ & $\theta_{\mathrm{ST}}$ & $\mathrm{R}_{\mathrm{ST}}$ \\
\hline Mphande-Nkhudzi & 5.6 & Shallow sandy bay & $\mathrm{n} / \mathrm{a}$ & $\mathrm{n} / \mathrm{a}$ & $0.013^{*}$ & 0.021 & $<0.001$ & $<0.001$ \\
\hline Nkhudzi-Mazinzi & 6.4 & Shallow sandy bay & $0.015^{*}$ & $0.046^{*}$ & $<0.001$ & $<0.001$ & $\mathrm{n} / \mathrm{a}$ & $\mathrm{n} / \mathrm{a}$ \\
\hline Mazinzi-Kanchedza & 4.3 & Shallow sandy bay & $0.006^{*}$ & 0.008 & 0.002 & $<0.001$ & $\mathrm{n} / \mathrm{a}$ & $\mathrm{n} / \mathrm{a}$ \\
\hline Nkhudzi-Kanchedza & 10.7 & Shallow sandy bay & $0.017 *$ & $0.054^{*}$ & 0.004 & 0.011 & $<0.001$ & $<0.001$ \\
\hline Kanchedza-Songwe & 2.4 & Shallow sandy bay & $0.007 *$ & 0.001 & 0.001 & 0.008 & 0.002 & $<0.001$ \\
\hline Songwe-Monkey Bay & 2.8 & Sand \& rock & $\mathrm{n} / \mathrm{a}$ & $\mathrm{n} / \mathrm{a}$ & $\mathrm{n} / \mathrm{a}$ & $\mathrm{n} / \mathrm{a}$ & $<0.001$ & 0.028 \\
\hline Nkukuti-Chirundu & 0.7 & Sandy/deep trough & $0.024^{*}$ & 0.020 & 0.001 & 0.018 & $\mathrm{n} / \mathrm{a}$ & $\mathrm{n} / \mathrm{a}$ \\
\hline Nkhudzi-Chirundu & c. 270 & $\begin{array}{l}\text { Sand, rock, river mouths } \\
\text { and deep water }\end{array}$ & $0.036^{*}$ & $0.208 *$ & $0.018 *$ & $0.051^{*}$ & $\mathrm{n} / \mathrm{a}$ & $\mathrm{n} / \mathrm{a}$ \\
\hline
\end{tabular}

For each pairwise comparison the table indicates the distance between the localities in kilometers, $\theta_{\mathrm{ST}}$, $\mathrm{R}_{\mathrm{ST}}$. Significance values after Bonferroni correction are indicated with an asterisk. $\mathrm{n} / \mathrm{a}=$ not applicable, as one of the localities was not sampled for this species.

Table 2 Comparison of levels of multilocus microsatellite estimates of population differentiation among Lake Malawi cichlid species with different habitat preferences

\begin{tabular}{llllll}
\hline Species & Habitat & $\begin{array}{l}\text { Distance } \\
(\mathrm{km})\end{array}$ & $\theta$ & $\mathrm{P}$ & Source \\
\hline Pseudotropheus zebra & Rock (mbuna) & 60 & 0.025 & $<0.05$ & Rico et al. (2003) \\
Pseudotropheus callainos & Rock (mbuna) & 60 & 0.077 & $<0.05$ & Rico et al. (2003) \\
P. (Tropheops) 'mauve' & Rock (mbuna) & 60 & 0.106 & $<0.05$ & Rico et al. (2003) \\
P. (Tropheops) 'olive' & Rock (mbuna) & 60 & 0.067 & $<0.05$ & Rico et al. (2003) \\
Melanochromis auratus & Rock (mbuna) & 42 & 0.151 & $<0.001$ & Markert et al. (1999) \\
Labeotropheus fuelleborni & Rock (mbuna) & 42 & 0.079 & $<0.001$ & Arnegard et al. (1999) \\
Protomelas taeniolatus & Rock (non-mbuna) & 280 & 0.026 & $<0.001$ & Present study \\
P. fenestratus & Rock/sand & 280 & 0.012 & $<0.001$ & Present study \\
P. similis & Sand & 20 & 0.001 & 0.198 & Present study \\
Copadichromis 'virginalis kajose' & Midwater inshore & 400 & 0.004 & 0.006 & Taylor \& Verheyen (2001) \\
Diplotaxodon macrops & Deep pelagic & 75 & $<0.001$ & 0.261 & Shaw et al. (2000) \\
Diplotaxodon 'offshore' & Deep pelagic & 175 & $<0.001$ & 0.291 & Shaw et al. (2000) \\
Diplotaxodon limnothrissa & Pelagic & 460 & 0.001 & 0.017 & Shaw et al. (2000) \\
\hline
\end{tabular}

P-values given are probabilities that the genetic structure estimate $(\theta)$ is zero. Shown are values for the maximum distances analysed for each species.

Because of the constraints on sampling, the clearest comparisons between species are obtained by viewing across rows of Table 1 . At all six pairs of sites where $\mathrm{P}$. taeniolatus and $P$. fenestratus were both sampled, $\theta$ and $R_{S T}$ were always lower in $\mathrm{P}$. fenestratus, indicating a weaker population structuring than in $\mathrm{P}$. taeniolatus. In comparison to $\mathrm{P}$. taeniolatus and P. fenestratus, P. similis showed the lowest values of both structure estimators for all comparable pairs of sites, with the exception of the $\theta$-values for the comparison between Kanchedza and Songwe, which were marginally lowest for P. fenestratus. To account for differences in the numbers of individuals sampled from different sites, the $\theta$ calculations were repeated three times with 22 individuals randomly subsampled from each species from each site.
The broad picture was unchanged: in comparisons of populations from the southern part of the lake only, the mean $\theta$-values for were 0.014 for P. taeniolatus (the same as for the full data set); 0.005 for P. fenestratus (compared to 0.004) and 0.002 for P. similis (compared to 0.001).

\section{Discussion}

Our study indicates that closely related Malawian haplochromine species can show very different patterns of population structure, in a manner that can be related to their habitat preferences. The rocky shore species Protomelas taeniolatus showed relatively high levels of population structuring, similar to those reported for mbuna (Table 2). 
With P. fenestratus, genetic differentiation was limited to comparisons between the northern and southern populations (over $270 \mathrm{~km}$ apart) and between the Mphande Island and other southern populations (Table 1 and other data not shown). The Mphande Island population lies at the southern extreme of this group of rocky-shore patches, and thus might be expected to show more divergence than those populations where gene flow along the coast from both north and south would be possible. The lack of population structure among the other southern populations and between the two headlands at Nkhata Bay indicates somewhat greater ability to cross sandy beaches or open bottom than is the case for mbuna or P. taeniolatus. Protomelas similis showed no significant population structuring over distances and habitat barriers that have been shown to cause population structuring both in mbuna and in more rock-bound species of Protomelas. Contrary to the suggestion by Fryer \& Iles (1972; p. 543), our results seem to suggest that shallow-water, sandy-shore species do not exist as finely subdivided populations in the manner of rocky-shore species, and so the potential for allopatric speciation in this group might be lower than it is presumed to be for mbuna. However, the spatial scale of our study is rather smaller than those of studies of benthic and pelagic zooplanktivorous species (Copadichromis, Diplotaxodon), which showed low levels of population structure over hundreds of kilometres (Table 2). It may be worth investigating the potential of more significant habitat barriers, such as long stretches of sheer rocky coasts, as along the northeastern shores, or the northwestern shore north of Nkhata Bay, and deep-water barriers isolating offshore islands such as Likoma and Chisumulu. An alternative explanation for allopatric speciation in taxa with low levels of population structuring might be past population fragmentation caused by extreme environmental changes. The water level of Lake Malawi has certainly fluctuated considerably (Sturmbauer et al. 2001).

\section{Acknowledgements}

R.P. was supported by a CONACyT scholarship, and M.I.T. by a NERC grant to G.F.T., C.R. and O. Seehausen. We thank the Malawi Ministry of Natural Resources (George Mkondiwa), the Malawi Department of Fisheries (Moses Banda and the late Sam Mapila) and National Parks and Wildlife (Leonard Sefu, Roy Bhima and Amuleke Msukwa) for co-operation in fieldwork, and J. Whitman for help with fish collection.

\section{References}

Aljanabi SM, Martinez I (1997) Universal and rapid salt extraction of high quality genomic DNA for PCR-based techniques. Nucleic Acids Research, 25, 4692-4693.

Arnegard ME, Markert JA, Danley PD, Stauffer JR Jr, Ambali AJ, Kocher TD (1999) Population structure and colour variation of the cichlid fish Labeotropheus fuelleborni Ahl along a recently formed archipelago of rocky habitat patches in southern Lake Malawi. Proceedings of the Royal Society of London B, 266, 119-130.

Balloux F, Brünner H, Lugon-Moulin N, Hausser J, Goudet J (2000) Microsatellites can be misleading: an empirical and simulation study. Evolution, 54, 1414-1422.

Danley PD, Markert JA, Arnegard ME, Kocher TD (2000) Divergence with gene flow in the rock-dwelling cichlids of Lake Malawi. Evolution, 54, 1725-1737.

Eccles DH, Trewavas E (1989) Malawian Cichlid Fishes: a Classification of Some Haplochromine Genera. Lake Fish Movies, Herten. Fryer G (1959) The trophic interrelationships and ecology of some littoral communities of Lake Nyasa with especial reference to the fishes and a discussion of the evolution of a group of rockfrequenting Cichlidae. Proceedings of the Zoological Society of London, 132, 153-281.

Fryer G, Iles TD (1972) The Cichlid Fishes of the Great Lakes of Africa: Their Biology and Evolution. Oliver \& Boyd, Edinburgh.

Goodman SJ (1997) R-ST Calc: a collection of computer programs for calculating estimates of genetic differentiation from microsatellite data and determining their significance. Molecular Ecology, 6, 881-885.

Goudet J (2001) FSTAT, a Program to Estimate and Test Gene Diversities and Fixation Indices, version 2.9.3. Available from http:// www.unil.ch/izea/softwares/fstat/html.

Kellogg KA, Markert JA, Stauffer JR, Kocher TD (1995) Microsatellite variation demonstrates multiple paternity in lekking cichlid fishes from Lake Malawi, Africa. Proceedings of the Royal Society of London B, 260, 79-84.

Konings A (2001) Malawi Cichlids in Their Natural Habitat, 3rd edn. Cichlid Press, El Paso, Germany.

Markert JA, Arnegard ME, Danley PD, Kocher TD (1999) Biogeography and population genetics of the Lake Malawi cichlid Melanochromis auratus: habitat transience, philopatry and speciation. Molecular Ecology, 8, 1013-1026.

Parker A, Kornfield I (1996) Polygynandry in Pseudotropheus zebra, a cichlid fish from Lake Malawi. Environmental Biology of Fishes, 47, 345-352.

Raymond M, Rousset F (1995) genepop Version 1.2: Population genetics software for exact tests and ecumenicism. Journal of Heredity, 86, 248-249.

Ribbink AJ, Marsh BA, Marsh AC, Ribbink AC, Sharp BJ (1983) A preliminary survey of the cichlid fishes of rocky habitats in Lake Malawi. South African Journal of Zoology, 18, 149-310.

Rico C, Bouteillon P, van Oppen MJH, Knight ME, Hewitt GM, Turner GF (2003) No evidence for parallel sympatric speciation in cichlid species of the genus Pseudotropheus from north western Lake Malawi. Journal of Evolutionary Biology, 16, 37-46.

Rico C, Turner GF (2002) Extreme microallopatric divergence in a cichlid species from Lake Malawi. Molecular Ecology, 11, 15851590.

Robinson RL, Ribbink AJ (1998) Abundance and seasonality of temporary cichlid breeding territories on a rocky shore in Lake Malawi, Africa. Ichthyological Explorations of Freshwaters, 8, 299312.

Shaw PW, Turner GF, Idid MR, Robinson RL, Carvalho GR (2000) Genetic population structure indicates sympatric speciation of Lake Malawi pelagic cichlids. Proceedings of the Royal Society of London B, 267, 2273-2280.

Sturmbauer C, Baric S, Salzburger W, Rüber L, Verheyen E (2001) Lake level fluctuations synchronize genetic divergences of cichlid fishes in African lakes. Molecular Biology and Evolution, 18, 144-154. 
Taylor MI, Verheyen E (2001) Microsatellite data reveals weak population substructuring in Copadichromis sp. 'virginalis kajose', a demersal cichlid from Lake Malawi. Journal of Fish Biology, 59, 593-604.

Turner GF (1994) Speciation in Lake Malawi cichlids: a critical review. Archiv für Hydrobiologie (Advances in Limnology), 44, 139-160.

Turner GF (1999) Explosive speciation of African cichlid fishes. In: Evolution of Biological Diversity (eds Magurran AE, May RM), pp. 113-129. Oxford University Press, Oxford.

van Oppen MJH, Rico C, Deutsch JC, Turner GF, Hewitt GM (1997) Isolation and characterisation of microsatellite loci in the cichlid fish Pseudotropheus zebra. Molecular Ecology, 6, 387-388.

Weir BS, Cockerham CC (1984) Estimating F-statistics for the analysis of population structure. Evolution, 38, 1358-1370.
This research is part of the $\mathrm{PhD}$ thesis of Ricardo Pereyra (University of East Anglia) carried out under the supervision of CR \& GFT. Martin Taylor is a NERC-funded postdoctoral researcher at the University of East Anglia, working on population structure and phylogenetics of Lake Malawi and Lake Victoria cichlid fish. Ciro Rico is now a Junta de Andalusia Research Fellow at the Doñana Research Station in Seville. He has a longstanding interest in the use of microsatellites to study paternity, population structure and mechanisms of speciation in fish. George Turner is Professor of Evolutionary Biology and Biodiversity and Deputy Director of the Hull Environment Research Institute at the University of Hull, and has a particular interest in speciation of Lake Malawi cichlids. 


\section{Appendix I}

Genetic variability of 18 populations of three species of Protomelas at five microsatellite loci. Number of alleles (NA), observed $\left(\mathrm{H}_{\mathrm{O}}\right)$ and expected $\left(\mathrm{H}_{\mathrm{E}}\right)$ heterozygosity. Significant deviations from Hardy-Weinberg equilibrium after sequential Bonferroni correction (by species) are asterisked

\begin{tabular}{|c|c|c|c|c|c|c|c|c|c|c|c|c|c|c|c|c|c|c|c|}
\hline & \multirow[b]{2}{*}{$\mathrm{n}$} & \multicolumn{3}{|c|}{ UME002 } & \multicolumn{3}{|c|}{ Pzeb3 } & \multicolumn{3}{|c|}{ UNH002 } & \multicolumn{3}{|c|}{ UME0003 } & \multicolumn{3}{|c|}{ UNH001 } & \multicolumn{3}{|c|}{ Mean } \\
\hline & & NA & $\mathrm{H}_{\mathrm{O}}$ & $\mathrm{H}_{\mathrm{E}}$ & NA & $\mathrm{H}_{\mathrm{O}}$ & $\mathrm{H}_{\mathrm{E}}$ & NA & $\mathrm{H}_{\mathrm{O}}$ & $\mathrm{H}_{\mathrm{E}}$ & NA & $\mathrm{H}_{\mathrm{O}}$ & $\mathrm{H}_{\mathrm{E}}$ & NA & $\mathrm{H}_{\mathrm{O}}$ & $\mathrm{H}_{\mathrm{E}}$ & NA & $\mathrm{H}_{\mathrm{O}}$ & $\mathrm{H}_{\mathrm{E}}$ \\
\hline \multicolumn{20}{|l|}{ P. taeniolatus } \\
\hline Nkhudzi & 70 & 26 & $0.829 *$ & 0.930 & 12 & 0.757 & 0.786 & 25 & 0.857 & 0.925 & 30 & $0.757^{*}$ & 0.947 & 18 & 0.887 & 0.938 & 22.6 & 0.817 & 0.905 \\
\hline Mazinzi & 47 & 28 & 0.957 & 0.954 & 9 & 0.745 & 0.782 & 21 & 0.872 & 0.912 & 32 & $0.723^{*}$ & 0.956 & 22 & $0.766^{*}$ & 0.933 & 22.4 & 0.813 & 0.907 \\
\hline Kanchedza & 50 & 32 & $0.840 *$ & 0.957 & 11 & 0.720 & 0.812 & 22 & $0.700^{*}$ & 0.929 & 36 & $0.760 *$ & 0.961 & 24 & 0.860 & 0.948 & 25.3 & 0.776 & 0.921 \\
\hline Songwe & 58 & 33 & 0.897 & 0.940 & 8 & 0.862 & 0.805 & 25 & $0.845^{*}$ & 0.932 & 39 & $0.845^{*}$ & 0.966 & 25 & $0.879 *$ & 0.940 & 26.0 & 0.866 & 0.920 \\
\hline Nkukuti & 50 & 29 & 0.980 & 0.956 & 9 & 0.500 & 0.531 & 19 & 0.800 & 0.863 & 32 & 0.900 & 0.958 & 27 & 0.880 & 0.916 & 21.4 & 0.802 & 0.845 \\
\hline Chirundu & 41 & 34 & 0.976 & 0.973 & 9 & 0.683 & 0.771 & 24 & 0.878 & 0.941 & 32 & 0.976 & 0.976 & 26 & 0.902 & 0.943 & 24.2 & 0.883 & 0.920 \\
\hline Overall /Mean & 316 & 30.3 & 0.924 & 0.954 & 9.6 & 0.722 & 0.743 & 22.6 & 0.825 & 0.917 & 33.5 & 0.873 & 0.960 & 23.6 & 0.862 & 0.937 & 23.7 & 0.826 & 0.903 \\
\hline \multicolumn{20}{|l|}{ P. fenestratus } \\
\hline Mphande & 48 & 30 & 0.938 & 0.948 & 9 & 0.813 & 0.758 & 20 & 0.896 & 0.919 & 28 & 0.917 & 0.951 & 21 & 0.792 & 0.913 & 21.6 & 0.871 & 0.901 \\
\hline Nkhudzi & 47 & 30 & 0.915 & 0.948 & 7 & 0.766 & 0.797 & 18 & 0.936 & 0.898 & 30 & 0.936 & 0.921 & 25 & 0.957 & 0.930 & 22.0 & 0.902 & 0.899 \\
\hline Kanchedza & 46 & 30 & 0.935 & 0.948 & 7 & 0.717 & 0.794 & 15 & 0.978 & 0.897 & 37 & 0.953 & 0.949 & 20 & 0.957 & 0.913 & 21.8 & 0.917 & 0.900 \\
\hline Mazinzi & 50 & 36 & 0.940 & 0.942 & 8 & 0.680 & 0.828 & 19 & 0.920 & 0.898 & 30 & 0.880 & 0.917 & 23 & $0.800^{*}$ & 0.931 & 23.2 & 0.844 & 0.903 \\
\hline Songwe & 47 & 28 & $0.894 *$ & 0.955 & 10 & 0.745 & 0.829 & 17 & 0.809 & 0.896 & 34 & $0.894 *$ & 0.950 & 23 & 0.872 & 0.923 & 22.4 & 0.843 & 0.911 \\
\hline Nkukuti & 49 & 37 & 0.918 & 0.971 & 8 & 0.735 & 0.773 & 26 & 0.959 & 0.942 & 30 & $0.857^{*}$ & 0.943 & 31 & $0.918 *$ & 0.960 & 26.4 & 0.878 & 0.918 \\
\hline Chirundu & 30 & 36 & 0.933 & 0.981 & 7 & 0.800 & 0.775 & 24 & 0.900 & 0.942 & 31 & $0.867 *$ & 0.975 & 26 & 0.900 & 0.958 & 24.6 & 0.880 & 0.926 \\
\hline Overall /Mean & 317 & 32.4 & 0.925 & 0.956 & 7.8 & 0.751 & 0.793 & 19.8 & 0.914 & 0.913 & 31.4 & 0.907 & 0.944 & 24.1 & 0.885 & 0.933 & 23.1 & 0.876 & 0.907 \\
\hline \multicolumn{20}{|l|}{ P. similis } \\
\hline Mphande & 46 & 41 & 0.957 & 0.942 & 10 & 0.848 & 0.835 & 25 & 0.957 & 0.945 & 34 & 0.739 & 0.942 & 31 & 0.957 & 0.965 & 28.2 & 0.891 & 0.932 \\
\hline Nkhudzi & 32 & 41 & 0.938 & 0.981 & 9 & 0.750 & 0.810 & 23 & 0.938 & 0.938 & 35 & 0.938 & 0.977 & 27 & 0.969 & 0.960 & 27 & 0.906 & 0.935 \\
\hline Kanchedza & 47 & 43 & 0.979 & 0.970 & 12 & 0.809 & 0.843 & 28 & 0.979 & 0.955 & 37 & 0.894 & 0.973 & 27 & 0.936 & 0.955 & 29.4 & 0.919 & 0.939 \\
\hline Songwe & 22 & 27 & 0.864 & 0.922 & 11 & 0.737 & 0.885 & 21 & 0.909 & 0.953 & 23 & 0.737 & 0.926 & 22 & 0.904 & 0.955 & 21.2 & 0.827 & 0.941 \\
\hline Monkey Bay & 22 & 30 & $0.727 *$ & 0.974 & 9 & 0.727 & 0.866 & 18 & 0.909 & 0.955 & 20 & $0.773^{*}$ & 0.952 & 20 & 0.909 & 0.944 & 19.4 & 0.809 & 0.938 \\
\hline Overall /Mean & 169 & 36.4 & 0.893 & 0.958 & 10.7 & 0.772 & 0.848 & 23 & 0.938 & 0.949 & 30.0 & 0.814 & 0.954 & 25.6 & 0.936 & 0.956 & 25.0 & 0.870 & 0.937 \\
\hline
\end{tabular}

